\title{
The source of duodenal aspirate in man
}

\author{
K. G. WORMSLEY \\ From the Royal Infirmary, Sheffield
}

During the past 30 years, analysis of duodenal contents after injection of secretin has been used to provide information about the function of the pancreas and, by induction, about its morphological status (Agren and Lagerlöf, 1936; Agren, Lagerlöf, and Berglund, 1936). However, recent investigation has shown that the electrolyte composition of aspirate from the human duodenum during stimulation with secretin appears to differ markedly from the composition of pancreatic juice obtained during experimental procedures from animals using cannulation of the pancreatic duct (Wormsley, 1968). It seems necessary, therefore, to re-examine the theoretical foundations upon which this type of test of pancreatic function is based.

Earlier investigations in dogs (Hart and Thomas, 1945; Conly, Crider, and Thomas, 1955; Dikstein and Birnbaum, 1960) and in man (Janowitz and Dreiling, 1962) had suggested that, during stimulation, the anions of pancreatic juice (and of human duodenal aspirate) bore a hyperbolic relationship to the flow rate of juice, with bicarbonate concentration increasing to constant maximal values with increasing flow rates, while chloride concentration fell in a reciprocal manner. From these findings it was concluded that a 'primary' juice of constant composition was secreted by the pancreas. However, neither pancreatic juice not duodenal aspirate is of constant composition and, indeed, study of human subjects, both in health and disease, has shown that over the range of flow rates found during secretin infusions in man, bicarbonate concentration decreases linearly with increasing rates of secretion into the duodenum, while the chloride concentration rises (Wormsley, 1968; Ribet, Pascal, and Sannou, 1967). These apparently discordant findings can only be resolved by assuming either that (a) the composition of duodenal aspirate does not accurately reflect the composition of pancreatic juice owing to admixture with non-pancreatic secretions (whose secretory characteristics and composition during stimulation differ from those of pancreatic juice), or $(b)$ if pancreatic juice is the major component of the fluid aspirated from the duodenum, then the fluctua- tions in composition of duodenal aspirate reflect parallel changes in the composition of pancreatic juice. (The differences in secretory characteristics and composition between pancreatic juice of animals and human duodenal aspirate are apparent rather than real and presumably indicate differences in species, technique, or interpretation of data.) Since it is not yet possible to measure accurately the flow of non-pancreatic secretions during secretin stimulation in man, detailed comparison of the patterns of electrolyte secretion in pancreatic juice and duodenal aspirate must be used to give an indirect estimate of the magnitude of the pancreatic contribution to the fluid aspirated from the duodenum.

From a study of published reports and from personal observations, it is clear that both pancreatic juice and duodenal aspirate undergo marked changes in electrolyte composition with changing conditions of stimulation, that is, marked changes occur in the concentrations of the individual anions, although the sum of the concentrations of the anions generally remains constant and approximately equal to the concentration of sodium. There are, for example, five types of situation in which both pancreatic juice and duodenal aspirate have been found to contain less bicarbonate and more chloride than expected, assuming, on the basis of current hypotheses, that 'primary' pancreatic secretion is of constant composition, with high bicarbonate and low chloride concentration.

1 Low bicarbonate and high chloride concentrations (with low rates of flow) have been shown to occur when stimulation of the pancreas is very weak. In the original report of Hart and Thomas (1945), the samples with low bicarbonate concentration at low rates of flow of pancreatic juice were almost all provided by experiments in which neutral peptone in the duodenum was used as the pancreatic stimulant. In experiments in which secretin was used to establish the 'hyperbolic' relationship (Conly et al, 1955; Dikstein and Birnbaum, 1960) very small doses were used to obtain the requisite low rates of flow.

2 Low bicarbonate concentrations are encountered as the effect of secretin stimulation wears off. It is 
characteristic of this situation that the bicarbonate concentration is less and chloride concentration greater than at similar flow rates during active secretin stimulation. Thus, with the data derived from the report of Birnbaum and Hollander (1965), it is possible to show that the concentration of bicarbonate is less during the second half hour after secretin injection than in similar volumes of pancreatic juice secreted during the first half hour. Lagerlöf, Schütz, and Holmer (1967) noted a similar fall in bicarbonate concentration after secretin injections in human studies.

3 'Low' bicarbonate concentrations, relative to flow rate, are found immediately after the onset of secretin stimulation, both in pancreatic juice (Birnbaum and Hollander, 1965) and in human duodenal aspirate (Lagerlöf $e t$ al, 1967).

4 When stimulation is prolonged, bicarbonate concentration tends to fall and chloride concentration to rise despite constant rates of secretion of juice. This phenomenon has been observed in the isolated pancreas (Rothman and Brooks, 1965a), in canine pancreatic juice during secretin stimulation (Komarov, Langstroth, and McRae, 1939; Christodoulopoulos, Jacobs, and Klotz, 1961), and in man (Banwell, Northam, and Cooke, 1967).

5 Bicarbonate concentration falls as the volume of pancreatic juice (Baron, Perrier, Janowitz, and Dreiling, 1963) and of duodenal aspirate (Wormsley, 1968; Ribet et al, 1967) increases, as the magnitude of the secretin stimulus is raised. This effect is not dependent on the duration of the stimulus.

In contrast to the above examples of 'inappropriately' low bicarbonate concentrations, high bicarbonate concentrations at low rates of flow have been encountered experimentally during periods of active stimulation of the pancreas by the coincident use of carbonic anhydrase inhibitors (Janowitz and Dreiling, 1962; Rawls, Wistrand, and Maren, 1963), anticholinergic drugs (Janowitz and Dreiling, 1962), and antidiuretic hormone (Perks, Schapiro, and Woodward, 1964). A number of recent reports (Werner and Mutt, 1954; Hartley, Gambill, and Summerskill, 1965; Lagerlöf et al, 1967) have shown that, in man, when large doses of secretin are given by single injection, low volumes of aspirate with high bicarbonate concentration can be obtained an hour or more after injection, bicarbonate concentration being better sustained than flow of water. With lower doses of secretin, on the other hand, neither rate of flow nor bicarbonate concentration are maintained.

Direct evidence about the changes in composition of human pancreatic juice must await satisfactory study of the cannulated human pancreas and is not yet available, since surgical drainage of the pancreas has usually been performed on diseased glands. However, in view of the parallel changes in electrolyte composition of the pancreatic juice of animals and human duodenal aspirate, under the experimental conditions outlined above, it seems permissible, at this time, to interpret the human response to secretin in terms of the mechanism of secretion of pancreatic juice.

\section{PANCREATIC SECRETION OF ELECTROLYTES}

Historically, interpretation of the electrolyte composition of pancreatic juice has been largely inspired by hypotheses of gastric secretion of electrolytes on the one hand and by models of renal tubular function on the other. As early as 1883, Heidenhain postulated that the acid-secreting cells of the stomach produced juice of constant composition. This view was also held by Pavlov (1910), who noted, however, that the composition of gastric juice was not constant and that the acid concentration was low during the early phases of gastric secretion. Pavlov suggested that admixture with mucus might explain the low acid concentration. The two-component hypothesis of gastric secretion, which assumes that gastric juice is composed of a 'parietal' (acid) component of constant composition and a nonparietal component (or components), was developed fully by Hollander (1952) and more recently by Makhlouf, McManus, and Card (1966). A second group of hypotheses to explain the variable composition of gastric juice was influenced by the observation that urine underwent changes in composition during passage through the renal tubule. Teorell (1947) suggested that 'primary' gastric juice, of constant composition, was modified by 'backdiffusion' of hydrogen ions through the gastric mucosa and that sodium ions entered the gastric lumen to replace the lost hydrogen ions. A variant of the 'back-diffusion' hypothesis was suggested by Hirschowitz (1960), who postulated a 'primary osmolar clearance' of sodium ions from plasma by the parietal cells, followed by 'barter' or exchange of hydrogen for the 'cleared' sodium ions.

Both the preceding groups of hypotheses have presumed that the product of the parietal cells remains constant at all rates of secretion of gastric juice. On the other hand, Rosemann (1907) concluded that although the anionic $\left(\mathrm{Cl}^{\prime}\right)$ composition of the 'primary' parietal juice was constant, the cationic composition $\left(\mathrm{H}^{\cdot}\right.$ and $\mathrm{Na} \cdot{ }^{\circ}$ ) changed with changes in the intensity of the gastric stimulus.

The three hypotheses of electrolyte secretion which have been invoked to explain the variable composition of gastric juice have also been applied to the secretion of electrolytes by the pancreas. The 
two-component hypothesis has become 'admixture', the back-diffusion hypothesis is represented by 'ductal modification' or 'ductal exchange of electrolytes', while a Rosemann-type hypothesis, which refers to changing anionic (and constant cationic) composition in the case of the pancreas, has not been presented as such, but is discussed below under the heading of 'salt-gland' secretion.

ADMIXTURE Secretion of 'non-alkaline' fluid, containing mainly chloride, by the pancreas could explain the low bicarbonate concentration of pancreatic juice at low rates of flow (Lim, Ling, Liu, and Yuan, 1936). However, output of chloride would have to be constant at all flow rates, in order to explain a 'hyperbolic' increase in bicarbonate concentration with increasing secretory rate (Bernier and Lambling, 1962). Moreover, it would be necessary to assume that under experimental conditions producing samples of low volume with high bicarbonate concentration, secretion of the 'non-alkaline' component had been suppressed to a greater degree than bicarbonate. In order to explain the decrease in bicarbonate concentration at constant rates of flow and the decrease in bicarbonate and chloride secretion when either anion is omitted from the nutrient solution surrounding the isolated pancreas (Rothman and Brooks, 1965a), there would have to be a very close link between the secretory mechanisms of the two components, or a breakdown of the normal mechanisms controlling the secretion of chloride.

Admixture with variable amounts of chloridecontaining fluid has also been invoked to explain the variations in composition of duodenal aspirate. Thus, mixture with 'basal' juice and bile has been invoked to explain the low bicarbonate concentration in duodenal aspirate after the onset of stimulation (Birnbaum and Hollander, 1965). Furthermore, secretion of fluid rich in chloride could explain the composition of the aspirate at flow rates greater than about $50 \mathrm{ml}$ in 10 minutes (Wormsley, 1968). The liver and biliary tract would appear to be the most probable source of diluting fluid in man, since secretin is known to stimulate the secretion of bile (Jonson, Sundman, and Thulin, 1964; Wheeler, 1965; Grossman, Janowitz, Ralston, and Kim, 1949). Alternatively, there might be an increase in the flow of fluid from the Brunner's glands or of extracellular fluid into the duodenal lumen.

Flow of bile into the duodenum must play some part in modifying pancreatic secretion in most subjects, since bilirubin is often present in duodenal aspirate stimulated by secretin. However, it is not yet possible to assess the degree of biliary admixture. Indirect evidence suggests that the biliary contribution is small and not of great significance in determin- ing the composition of duodenal aspirate during secretin stimulation. Thus, both the output of anions and the relationship of anionic concentration to volume of aspirate are similar in bile-stained juice and in aspirate free from bile pigment both in normal subjects and in patients with chronic pancreatitis or obstruction of the biliary tract. Moreover, the choleretic action of secretin is relatively slight in dogs (Jonson et al, 1964; Wheeler, 1965) and human subjects (Grossman et al, 1949) but, on the other hand, secretion of both water and electrolytes is considerably increased in the cat (Scratcherd, 1965). A recent study of the isolated (pig) liver (Hardison and Norman, 1967) has shown that the electrolyte content of the bile produced in response to secretin has bicarbonate and chloride concentrations as high as those in pancreatic juice. When the dose of secretin was increased, the bicarbonate concentration in the bile did not fall from the very high levels ( $>100$ m-equiv/ 1) evoked by lower doses of secretin. Clearly, a hepato-biliary response to secretin of this type could not explain the findings in human duodenal aspirate. Further study of the electrolyte composition of human bile is therefore required, since the information available at this time is unsatisfactory and incomplete.

Cooke and Grossman (1966) found that Boots' secretin (but not Vitrum secretin) stimulated the secretion of fluid with the characteristics of extracellular fluid from pouches of Brunner's glands in dogs. However, this effect was quantitatively slight compared with the effect of secretin on the pancreas. In this connexion, it is of interest that human duodenal aspirate is free of glucose at all flow rates and the concentration of urea is inversely related to the rate of flow, suggesting that there is no direct flow of extracellular fluid into the duodenal lumen during stimulation with secretin in man (Wormsley, 1968).

It is, of course, possible that the pancreas is the source of the increasing amounts of sodium chloride secreted into the duodenum during high rates of flow of juice. An indication that increasing amounts of chloride are indeed produced by the pancreas at high flow rates can be found in the report of Baron et al (1963), who note that with 'supramaximal' doses of secretin, dogs produce increased volumes of pancreatic juice with decrease in the concentration of bicarbonate, but relatively constant bicarbonate output. More recently, changes in the anionic composition of pancreatic juice of dogs, exactly similar to those in human duodenal aspirate, have been found at high rates of flow and with large doses of secretin (J. P. Pascal, personal communication). 
Although the output of chloride is 'normal' in patients with chronic pancreatitis (Wormsley, 1968), it is not possible to draw any conclusions about the source of the chloride from this fact. The chloriderich (and enzyme-deficient) juice from the pancreas of dogs treated with ethionine resembles the secretion of patients with chronic pancreatitis (Feldman, Dreiling, Paulino-Netto, Schaffner, and Janowitz, 1963) but no direct evidence is available to show whether, in these patients, the chloride is derived from the pancreas, and denotes a 'second component' of pancreatic juice, or originates outside the pancreas. On the other hand, comparison of the bicarbonate secretion of normal subjects and patients with chronic pancreatitis indicates that pancreatic bicarbonate secretion determines both the pattern and the magnitude of bicarbonate production in man, whatever the origin of the chloride.

DUCTAL MODIFICATION A second hypothesis to explain the low bicarbonate concentration of pancreatic juice at low rates of flow postulates that bicarbonate is secreted by the pancreatic cells and is exchanged with chloride across the pancreatic ductal epithelium, with greater exchange, and therefore less bicarbonate in the resultant juice, at lower rates of flow (Janowitz and Dreiling, 1962). Alternatively, it was suggested that the total amount of anion transported through the ductal wall might be constant and independent of the flow rate (Dikstein and Birnbaum, 1960). Recently, in apparent confirmation of 'ductal modification', it has been shown that when fluid rich in bicarbonate is experimentally perfused through the main duct of the pancreas, bicarbonate disappears at low rates of perfusion and is replaced by chloride (Case, Harper, and Scratcherd, 1966; Wastell, Rudick, and Dreiling, 1966). However, the 'ductal modification" hypothesis in this form cannot account for samples of juice of low volume with high bicarbonate concentration for the dependence of composition of juice on the duration of the test and for the inverse relationship of flow rate and bicarbonate concentration at high rates of flow. It would be necessary to assume that exchange of chloride for bicarbonate occurred only at very low and very high rates of flow of juice, or levels of secretin stimulation, and that the permeability of the ductal epithelium increased during prolonged secretin stimulation. Alternatively, it might be suggested that most of the bicarbonate originated in the ductal wall and was transported into the ductal lumen under the influence of secretin and that this transport mechanism had an upper limit. The 'primary' secretion in this case would have to be sodium chloride rather than sodium bicarbonate.
'Ductal modification' of pancreatic juice has been considered capable of explaining the changes in composition of duodenal aspirate in man (Janowitz and Dreiling, 1962), particularly the low bicarbonate concentration found with low rates of secretion into the duodenum. However, it is much more difficult to explain the characteristics of the aspirate at high flow rates on the basis of this mechanism alone.

PANCREATIC 'INHIBITION', 'EXHAUSTION', AND 'PHARMACOlOGical STIMUlation' Previous workers, who had noted 'inappropriate' bicarbonate concentration of pancreatic juice or duodenal aspirate, had suggested that the results were artefactualand denoted 'inhibition' or 'exhaustion' of the pancreas. Thus, the low bicarbonate concentrations found in duodenal aspirate after starting stimulation with secretin (Lagerlöf et al, 1967), and when using large doses of secretin (Banwell et al, 1967), were attributed to 'inhibition' on the basis of the inhibition of pancreatic bicarbonate secretion in dogs given supramaximal doses of secretin (Baron et al, 1963). However, it should be noted that the very unreliable Vitrum secretin was used in most studies in which inhibition was demonstrated, and, until pure stable secretin is shown to produce inhibition of electrolyte secretion, this phenomenon must be considered not proven. Moreover, it is not necessarily valid to extend evidence purporting to show inhibition of pancreatic electrolyte secretion in dogs to human studies, since, for example, gastric secretion of electrolytes can be 'inhibited' by supramaximal doses of gastrin in dogs, but not in cats or man (Emås and Grossman, 1967).

The gradual fall in bicarbonate concentration and rise in chloride concentration of pancreatic juice during prolonged secretin stimulation has been attributed to 'exhaustion' of the pancreas (Christodoulopoulos et al, 1961). However, it seems unlikely that exhaustion can explain the fall in bicarbonate concentration with increasing volumes of duodenal aspirate in man, since bicarbonate output remains constant or continues to rise under these conditions. Moreover, if the dose rate of secretin infusion is decreased after a high rate of infusion, the secretory rate and concentration and output of bicarbonate return to values similar to, or somewhat greater than, the response to the same lower dose rate given before the higher rate of infusion (Wormsley, unpublished observations). For these reasons, it also seems unlikely that systemic changes, such as metabolic acidosis, can be responsible for the change in composition of the duodenal aspirate. In any case, the response to experimental metabolic acidosis consists of a marked reduction in the volume of pancreatic juice, without any significant change in 
the electrolyte composition (Rawls et al, 1963; Pak, Hong, Pak, and Hong, 1966).

It is not clear whether the response to secretin at high rates of flow denotes 'physiological' secretion of sodium chloride or represents a 'pharmacological' artefact produced by the use of high dose rates of secretin. Every human subject secretes both bicarbonate and chloride in response to secretin and although larger volumes of fluid, containing more bicarbonate and chloride, are secreted in response to increasing doses of secretin, the overall relationship between the concentration of anions and volume of fluid is independent of the dose rate of secretin. The total amount of bicarbonate, chloride, and fluid secreted in response to any dose of secretin depends on the 'sensitivity' of each subject to secretin and on the health of the electrolyte-secreting elements. The definition of 'sensitivity' in this context depends on whether $(a)$ the mechanism of secretion of bicarbonate and chloride are linked. Under these circumstances, individual characteristics will determine the total output of anions and the proportion of chloride to bicarbonate at any dose level of secretin, which in turn determines the dose level of secretin which evokes maximal bicarbonate secretion. (b) Whether the mechanisms of secretion of chloride are wholly or partly independent of bicarbonate secretion. Both bicarbonate and chloride outputs increase with increasing dose rates of secretin, but while bicarbonate predominates at low flow rates of juice in normal subjects, the aspirate contains increasing amounts of chloride at flow rates greater than about $50 \mathrm{ml}$ in 10 minutes, suggesting that the chloride-secreting mechanism may be less sensitive to secretin than the bicarbonate-secreting mechanism. The relationship between the dose level of secretin and total output of anions (and volume of fluid) would depend both on the 'overall' and the 'relative' sensitivities of the bicarbonate and chloride-secreting mechanisms under these circumstances.

While most normal subjects show a steady volume response to constant-rate infusions of secretin, and secrete mainly bicarbonate until the maximal bicarbonate response has been attained, some individuals respond to secretin in a different manner, in that even low dose rates of secretin evoke continuously increasing volumes of water and chloride, although the bicarbonate response at this level of stimulation may be much less than maximal (Wormsley, 1968). In these subjects, there is either failure of the mechanisms normally linking bicarbonate and chloride secretion or the chloride-secreting elements are much more 'sensitive' than normal. Since in any population group there appears to be no clear distinction between 'physiological', 'pharmacological', and 'pathological' secretion of chloride, more studies are required to determine whether, in different individuals, increasing degrees of stimulation with secretin produce qualitative changes in the secretory elements or in the source of duodenal juice.

SALT-SECRETING GLAND The close relationship between bicarbonate and chloride secretion in pancreatic juice can be explained by assuming that the pancreas is a 'salt-secreting' gland, producing a juice which is not of constant concentration or composition. Under the influence of secretin stimulation, bicarbonate replaces the anionic component $\left(\mathrm{Cl}^{\prime}\right)$ of the secretion just as the stomach modifies the main cation. On the basis of this mechanism, the 'inappropriately' low bicarbonate and high chloride concentration found at the onset or after stopping stimulation, or with stimulation of low intensity, indicates incomplete stimulation of the electrolyte-secreting mechanisms of the pancreatic cells. With stimuli greater than 'maximal', the capacity to secrete bicarbonate instead of chloride might be surpassed and 'primary' sodium chloride secreted instead.

There is some evidence for a 'unicellular' origin of pancreatic juice. Ball, Tucker, Solomon, and Vennesland (1941) found that the content of bicarbonate in pancreatic cells was much less than the concentration found in the secreted juice, while the chloride content of the cells was greater than in most other cells of the body. Rothman and Brooks (1965a and b, 1966), in their study of the secretion of the isolated pancreas, found that substitution of sulphate for chloride in the bathing medium stopped bicarbonate secretion, suggesting that sodium bicarbonate and chloride secretion were 'coupled in some manner' and that these electrolytes might be secreted by the same cells. Rothman and Brooks concluded that chloride secretion in the isolated pancreas could not be attributed to passive diffusion but was due to active transport, although they were unable to provide full details of the electrochemical gradients involved in the transport process.

It is clear that the pancreas does secrete both bicarbonate and chloride, but whether the chloride of pancreatic juice is derived from the same cells as the bicarbonate or whether these two anions originate from different parts of the gland can only be decided by study of the mechanisms by which the individual secretory elements of the pancreas produce electrolytes. In addition, the nature of electrolyte secretion will determine how, for instance, concepts such as 'maximal pancreatic capacity to secrete bicarbonate' are to be interpreted. Thus, if the pancreatic cells secrete juice of constant composition, then the maximal bicarbonate response 
indicates maximal recruitment of the secretory elements. Submaximal output of bicarbonate is then due to submaximal rates of secretion by the individual secretory elements or incomplete recruitment of the individual secretory units if the latter secrete in an 'all-or-none' manner, that is, if the secretory rate of each unit is constant, or a combination of these. There would have to be two populations of cellssecreting bicarbonate and secreting chloride, respectively. If the pancreatic cells secrete electrolytes in a graded manner, from the point of view of composition, rate, and recruitment, or any combination of these, then the composition of the secreted juice will be variable and maximal bicarbonate output will be determined by factors other than 'maximal secretory cell mass', such as the total mass of the appropriate transport (or enzyme) systems and factors regulating the degree of saturation.

In man, interpretation of maximal bicarbonate response in terms of pancreatic function is, of course, complicated by the additional bicarbonate derived from bile and duodenal juices, since the contribution of bicarbonate from these two sources cannot yet be measured directly. Indirect evidence is provided by the bicarbonate secretion of patients with chronic pancreatitis whose maximal bicarbonate response ranges from 20 to $50 \%$ of normal (Wormsley, 1968). However, until the nature and degree of derangement of pancreatic bicarbonate secretion in chronic pancreatitis can be assessed, this sort of evidence must be interpreted with caution, since it is not possible to exclude residual bicarbonate secretion in these patients, just as residual secretion of digestive enzymes often persists.

Although this review has discussed at length the uncertain sources of the duodenal aspirate, it is worth emphasizing in conclusion that in practice the response to secretin is of great value in detecting pancreatic insufficiency.

\section{REFERENCES}

Agren, G., and Lagerlöf, H. (1936). The pancreatic secretion in man after intravenous administration of secretin. Acta med. scand., 90, 1-29.

-,$\frac{1}{2}$, and Berglund, H. (1936). The secretin test of pancreatic function in the diagnosis of pancreatic disease. Ibid., 90, 224-271.

Ball, E. G., Tucker, H. F., Solomon, A. K., and Vennesland, B. (1941). The source of pancreatic juice bicarbonate. J. biol. Chem., 140, 119-129.

Banwell, J. G., Northam, B. E., and Cooke, W. T. (1967). Secretory response of the human pancreas to continuous intravenous infusion of secretin. Gut, 8, 50-57.

Baron, J. H., Perrier, C. V., Janowitz, H. D., and Dreiling, D. A. (1963). Maximum alkaline (bicarbonate) output of the dog pancreas. Amer. J. Physiol., 204, 251-256.

Bernier, J. J., and Lambling, A. (1962). Relations between the volume and output of bicarbonate in pancreatic secretion. In Ciba Foundation Symposium on the Exocrine Pancreas. Edited by
A. V. S. de Reuck and M. P. Cameron, pp. 138-149. Churchill, London.

Birnbaum, D., and Hollander, F. (1965). Relation between bicarbonate concentration and rate of canine pancreatic secretion. Amer. $J$. Physiol., 209, 966-972.

Case, R. M., Harper, A. A., and Scratcherd, T. (1966). The relationship between bicarbonate and chloride in pancreatic juice. J. Physiol. (Lond.), 182, 49-50P.

Christodoulopoulos, J. B., Jacobs, W. H., and Klotz, A. P. (1961). Action of secretin on pancreatic secretion. Amer. J. Physiol., 201, 1020-1024.

Conly, S. S., Crider, J. O., and Thomas, J. E. (1955). Relation of bicarbonate concentration of pancreatic juice to rate of secretion. Ibid., 182, 97-99.

Cooke, A. R., and Grossman, M. I. (1966). Studies on the secretion and motility of Brunner's gland pouches. Gastroenterology, 51, 506-514.

Dikstein, S., and Birnbaum, D. (1960). The mechanism of external pancreatic secretion. Experientia (Basel), 16, 365-367.

Emås, S., and Grossman, M. I. (1967). Comparison of gastric secretion in conscious dogs and cats. Gastroenterology, 52, 29-34.

Feldman, M., Dreiling, D. A., Paulino-Netto, A., Schaffner, F., and Janowitz, H. D. (1963). Effect of $d$-l-ethionine on electrolyte secretion of the dog pancreas. Amer. J. Physiol., 205, 878-884

Grossman, M. I., Janowitz, H. D., Ralston, H., and Kim, K. S. (1949). The effect of secretin on bile formation in man. Gastroenterology, $12,133-138$.

Hardison, W. G., and Norman, J. C. (1967). Effect of bile salt and secretin upon bile flow from the isolated perfused pig liver. Ibid., 53, 412-417.

Hart, W. M., and Thomas, J. E. (1945). Bicarbonate and chloride of pancreatic juice secreted in response to various stimuli. Ibid., 4, 409-420.

Hartley, R. C., Gambill, E. E., and Summerskill, W. H. J. (1965). Pancreatic volume and bicarbonate output with augmented doses of secretin. Ibid., 48, 312-317.

Heidenhain, R. (1883). Physiologie der Absonderungsvorgänge. In Handbuch der Physiologie, vol. 5, pt. 1, pp. 1-419. Edited by L. Hermann. Vogel, Leipzig.

Hirschowitz, B. I. (1960). Gastric osmolar clearance and ionic barter: two mechanisms of electrolyte secretion by the human stomach. J. appl. Physiol., 15, 933-938.

Hollander, F. (1952). Gastric secretion of electrolytes. Fed. Proc., 11, 706-714.

Janowitz, H. D., and Dreiling, D. A. (1962). The pancreatic secretion of fluid and electrolytes. In Ciba Foundation Symposium on the Exocrine Pancreas. Edited by A. V. S. de Reuck and M. P. Cameron, pp. 115-137. Churchill, London.

Jonson, G., Sundman, L., and Thulin, L. (1964). The influence of chemically pure secretin on hepatic bile output. Acta physiol. scand., 62, 287-290.

Komarov, S. A., Langstroth, G. O., and McRae, D. R. (1939). The secretion of crystalloids and protein material by the pancreas in response to secretin administration. Canad. J. Res., 17 (Sect. D), 113-123.

Lagerlöf, H. O., Schütz, H. B., and Holmer, S. (1967). A secretin test with high doses of secretin and correction for incomplete recovery of duodenal juice. Gastroenterology, 52, 67-77.

Lim, R. K. S., Ling, S. M., Liu, A. C., and Yuan, I. C. (1936) Quantitative relationships between the basic and other components of pancreatic secretion. Chin. J. Physiol., 10, 475-491.

Makhlouf, G. M., McManus, J. P. A., and Card, W. I. (1966). A quantitative statement of the two-component hypothesis of gastric secretion. Gastroenterology, 51, 149-171.

Pak, B. H., Hong, S. S., Pak, H. K., and Hong, S. K. (1966). Effects of acetazolamide and acid-base changes on biliary and pancreatic secretion. Amer. J. Physiol., 210, 624-628.

Pavlov, I. P. (1910). The Work of the Digestive Glands, 2nd ed. Translated by W. H. Thompson. Griffin, London.

Perks, A. M., Schapiro, H., and Woodward, E. R. (1964). The influence of antidiuretic hormone on pancreatic exocrine secretion. Acta Endocr. (Kdh.), 45, 340-348.

Rawls, J. A., Jr, Wistrand, P. J., and Maren, T. H. (1963). Effects of acid-base changes and carbonic anhydrase inhibition on pancreatic secretion. Amer. J. Physiol., 205, 651-657.

Ribet, A., Pascal, J. P., and Sannou, N. (1967). Etude de la fonction exocrine du pancréas humain par les perfusions continues sécrétine. Arch. Mal. Appar. dig., 56, 677-684. 
Rosemann, R. (1907). Beiträge zur Physiologie der Verdauung. I. Die Eigenschaften und die Zusammensetzung des durch Scheinfütterung gewonnenen Hundemagensaftes. Pflügers Arch, ges. Physiol., 118, 467-524.

Rothman, S. S., and Brooks, F. P. (1965a). Pancreatic secretion in vitro in ' $\mathrm{Cl}$-free', ' $\mathrm{CO}_{2}$-free' and low- $\mathrm{Na}+$ environment. Amer. J. Physiol., 209, 790-796.

- (1965b). Electrolyte secretion from rabbit pancreas in vitro. Ibid., 208, 1171-1176.

- 1 (1966). Chloride, the 'other' anion of pancreatic secretion. Amer. J. dig. Dis., 11, 251-256.

Scratcherd, T. (1965). Electrolyte composition and control of biliary secretion in the cat and rabbit. In The Biliary System: $A$ Symposium of the NATO Advanced Study Institute. Edited by
W. Taylor, pp. 515-529. Blackwell, Oxford.

Teorell, T. (1947). Electrolyte diffusion in relation to the acidity regulation of the gastric juice. Gastroenterology, 9, 425-443.

Wastell, C., Rudick, J., and Dreiling, D. A. (1966). Diffusion of bicarbonate across pancreatic duct epithelium. Surg. Forum, 17, 339-341.

Werner, B., and Mutt, V. (1954). The pancreatic response in man to the injection of highly purified secretin and of pancreozymin. Scand. J. clin. Lab. Invest., 6, 228-236.

Wheeler, H. O. (1965). Inorganic ions in bile. In The Biliary System: A Symposium of the NATO Advanced Study Institute. Edited by W. Taylor, pp. 481-493. Blackwell, Oxford.

Wormsley, K. G. (1968). Response to secretin in man. Gastroentero$\log y, 54,197-209$. 